\title{
Single polyp Acropora recruit resists overgrowth by the pervasive macroalgae Lobophora
}

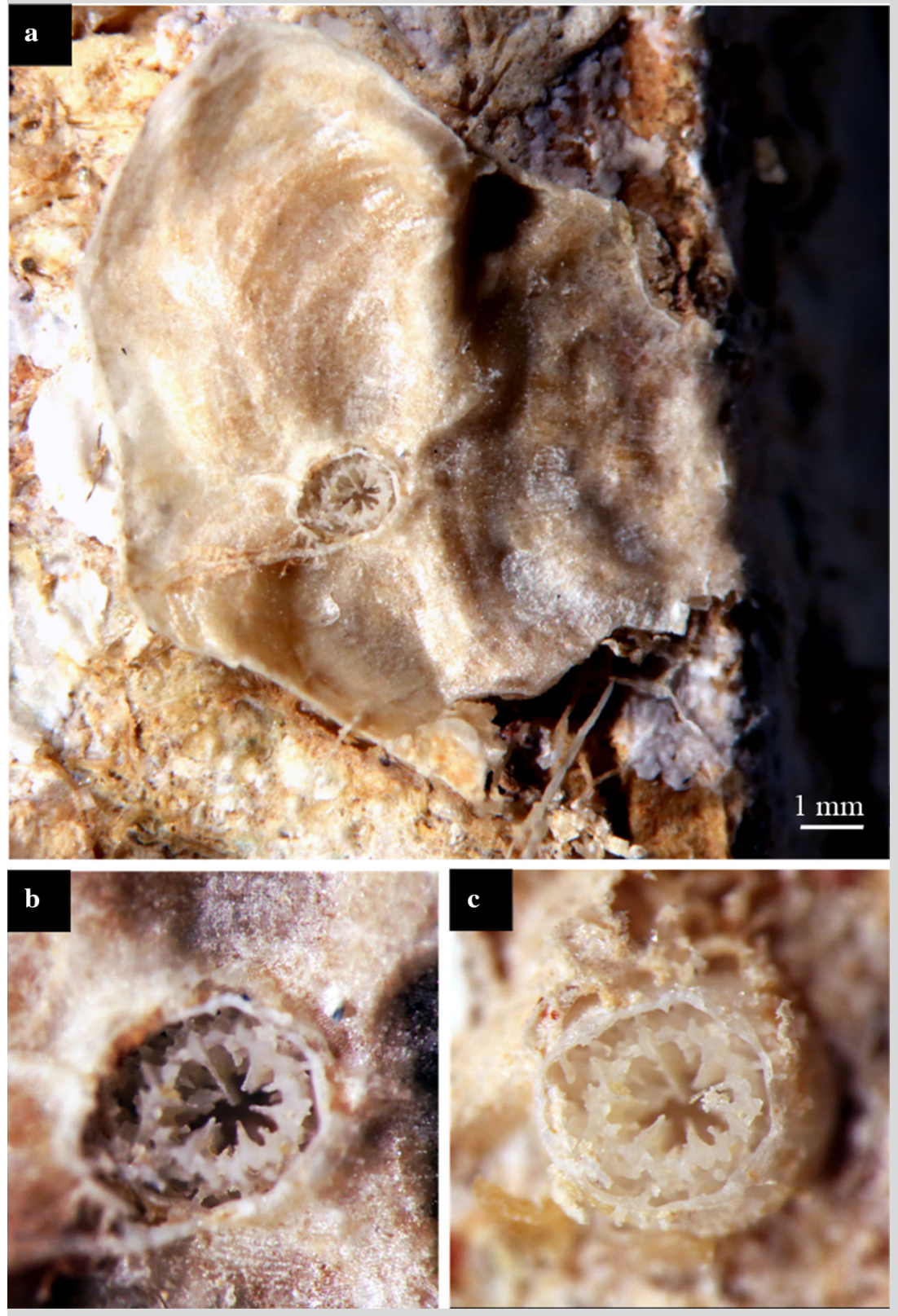

Fig. 1 a Competitive interaction between the Acropora recruit resisting Lobophora overgrowth, and close-ups of the recruit $\mathbf{b}$ surrounded by the thallus and $\mathbf{c}$ after thallus removal
Due to the minute size of newly settled corals, overgrowth by competitors is one of the dominant causes of post-settlement mortality, and the pervasive brown macroalgae Lobophora is a common competitor. Due to its often encrusting growth form and allelopathic toxicity, Lobophora is known to reduce coral recruitment (Doropoulos et al. 2017) as well as juvenile coral growth and survival (Box and Mumby 2007). Given these known effects, it was surprising to observe a recently settled Acropora recruit that had resisted overgrowth by the thallus of an encrusting Lobophora (Fig. 1).

The Acropora recruit was a single polyp individual approximately 4 weeks in age, measuring $1.5 \mathrm{~mm}$ in diameter with a fully developed skeleton. It was located on the underside of a settlement tile being used to quantify coral recovery in north-west Australia. Most striking was the nature of the competitive interaction. The thallus of the Lobophora had formed a hole that completely surrounded the Acropora (Fig. 1a, b), yet both appeared healthy with no signs of degradation on either the algal thallus or the coral skeleton. The growth form of the recruit was somewhat tubular, elongating much more in height (Fig. 1c) than single polyp Acropora recruits of similar diameter (pers. obs.). This elongated growth form and raised rim of the recruit are likely a response to direct competition with the expanding Lobophora thallus. Potentially, the recruit also used its mesenterial filaments to combat the algae as it grew over the top, resulting in the circular hole in the algal tissue. Adult Acropora have been observed to use their mesenterial filaments to sweep detritus and turf to create space for growth (Roff et al. 2009). While this observation demonstrates that newly settled coral recruits have the capacity to compete with and resist algal overgrowth, it is likely an exception rather than a rule.

\section{References}

Box SJ, Mumby PJ (2007) Effect of macroalgal competition on growth and survival of juvenile Caribbean corals. Mar Ecol Progr Ser 342:139-149

Doropoulos C, Roff G, Visser M-S, Mumby PJ (2017) Sensitivity of coral recruitment to subtle shifts in early community succession. Ecology 98:304-314

Roff G, Dove SG, Dunn SR (2009) Mesenterial filaments make a clean sweep of substrates for coral growth. Coral Reefs 28:79

C. Doropoulos (D) (凶)

CSIRO Oceans and Atmosphere, Dutton Park, QLD 4102, Australia

e-mail: christopher.doropoulos@csiro.au

Received: 9 July 2017/ Accepted: 26 July 2017/Published online: 2 August 2017

Coral Reefs (2017) 36:1211

(C) Springer-Verlag GmbH Germany 2017

DOI $10.1007 / \mathrm{s} 00338-017-1612-7$ 